\title{
Comparison of single-breath and tidal breathing exhaled nitric oxide levels in infants
}

\author{
P.J. Franklin*, S.W. Turner*, R.C. Mutch*, S.M. Stick*\#
}

Comparison of single-breath and tidal breathing exhaled nitric oxide levels in infants. P.J. Franklin, S.W. Turner, R.C. Mutch, S.M. Stick. C ERS Journals Ltd 2004.

ABSTRACT: The aim of this study was to compare two different methods, tidal breathing (TB) and single-breath (SB), for measuring fractional exhaled nitric oxide (FENO) in infants.

FENO was measured in 71 infants with either recurrent wheeze $(n=32)$, recurrent cough $(n=16)$ or no symptoms (healthy, $n=23$ ) using both methods. For TB measurements five breaths were collected into a gas sampling bag (off-line reservoir sampling). The SB method was modified from the raised volume rapid thoracoabdominal technique. Agreement between the two methods was investigated and both methods were used to compare FENO in infants with and without symptoms.

Flow dependence of SB FENO was demonstrated using two expiratory flows (11 and $\left.40 \mathrm{~mL} \cdot \mathrm{s}^{-1}\right)$. There was a moderate correlation $(r=0.60)$ but poor agreement between levels using the TB and SB methods. A significant difference in FENO between healthy children and children with wheeze was found using the SB but not the TB method.

Due to lower expiratory flow and reduced nasal nitric oxide contamination the singlebreath technique may be more sensitive than the tidal breathing method for detecting differences in exhaled nitric oxide between infants with and without respiratory symptoms.

Eur Respir J 2004; 23: 369-372.
*School of Paediatrics and Child Health, University of Western Australia, and ${ }^{\#}$ Dept of Respiratory Medicine, Princess Margaret Hospital for Children, Perth, Australia.

Correspondence: P. Franklin, School of Paediatrics and Child Health, University of Western Australia, GPO BOX D184, Perth 6840, Australia.

Fax: 61893882097

E-mail: peterf@ichr.uwa.edu.au

Keywords: Exhaled nitric oxide, infants, singlebreath, tidal breathing

Received: July 222003

Accepted after revision: October 142003

This study was funded by the National Health and Medical Research Council. The Seivers NOA 280 nitric oxide analyser was bought using an unrestricted grant from GlaxoWellcome, Australia.
Measuring exhaled nitric oxide (NO) (fractional exhaled nitric oxide (FENO)) is a simple, noninvasive test that is thought to reflect eosinophilic airway inflammation [1]. There have been suggestions that FENO may be useful for the monitoring and management of asthma [1]. As most childhood asthma begins in infancy [2] FENO may provide a tool to identify infants who wheeze due to asthma [3]. Indeed, BARALDI et al. [4] showed that FENO measurements were raised in acutely wheezing infants and reduced to normal after inhaled steroid treatment, while the current authors have previously reported increased FENO in clinically stable infants with a history of wheeze [5]. Conversely, RATJEN et al. [6] reported that FENO was reduced in infants who presented with first-time wheezy bronchitis. These findings suggest that FENO may be able to differentiate between viralinduced and recurrent wheezing in infants.

In infants FENO has been measured during tidal breathing (TB) $[4,6,7]$ as well as using a modified single breath (SB) technique [5]. As infants are unable to actively cooperate with breath collections TB measurements seem to offer the simplest way to measure FENO in this age group. However, various important methodological issues, such as expiratory flow and nasal NO contamination, cannot be controlled during TB. The SB method controls for flow and excludes nasal NO contamination, however, it requires the child to be sedated and can only be performed with specialised equipment. The aim of the present study was to compare FENO in wheezy and healthy infants using both TB and SB methods. The current authors hypothesised that there would be a poor agreement but a good correlation between levels collected using the two methods. Furthermore, since most populations of wheezy infants are heterogenous and only a proportion are likely to have asthma, the authors hypothesised that, due to lower expiratory flows and reduced nasal NO contamination with the SB technique, it would be more sensitive than the TB method to detect a group mean shift in FENO.

\section{Methods}

\section{Subjects and protocol}

A total of 23 healthy and 32 recurrent wheezy infants had FENO measured using both TB and SB techniques. Infants were classified as recurrent wheezers if they had a history of three or more episodes of wheeze or wheezing on most days for $>1$ month. A third group of 16 infants whose parents reported on-going problems of cough or rattle, without colds, was also included in the study. All of these children were well at the time of testing. Details of all infants are presented in table 1.

Infants were assessed clinically prior to testing and parents completed a questionnaire to gather information on the infants' history of respiratory symptoms, as well as a family history of allergy. Infants underwent measurements of lung function, TB and SB FENO. Lung function was assessed using the raised volume rapid thoraco-abdominal compression technique [8]. Infants were studied in the supine position, asleep following an oral dose of chloral hydrate $\left(60-100 \mathrm{mg} \cdot \mathrm{kg}^{-1}\right)$. Tidal FENO was always collected first and SB FENO measured prior to lung function measurements. Written 
Table 1. - Subject characteristics

\begin{tabular}{lccc}
\hline & Healthy & Coughers & Wheezers \\
\hline Subjects n & 23 & 16 & 31 \\
M/F & $12 / 11$ & $10 / 6$ & $24 / 7$ \\
Age weeks & $40.1(21.2)$ & $54.9(23.3)$ & $52.9(24.3)$ \\
Height cm & $71.7(5.7)$ & $75.7(6.4)$ & $75.0(6.3)$ \\
Weight kg & $8.9(1.6)^{\#}$ & $10.2(1.4)$ & $10.3(2.0)$ \\
FEV $0.5 \mathrm{~mL} \cdot \mathrm{s}^{-1}$ & $179.2(42.6)$ & $186.9(49.9)$ & $173.7(36.9)^{\bullet}$ \\
SB FENO ppb & $23.2(18.3-29.4)^{+}$ & $27.9(21.1-37.1)$ & $32.9(26.1-41.6)$ \\
TB FENO ppb & $13.8(10.4-18.3)$ & $12.6(8.0-20.0)$ & $15.6(13.1-18.5)$
\end{tabular}

Data are presented as mean (SD) or geometric mean $(95 \%$ confidence interval) unless otherwise stated. M: male; F: female; FEV0.5: forced expiratory volume in 0.5 seconds; SB FENO: single breath fractional exhaled nitric oxide; TB FENO: tidal breathing exhaled nitric oxide. \#: significantly lower than both wheezy and coughing groups $(\mathrm{p}=0.02)$; $\because$ : significantly lower than healthy group after controlling for age $(\mathrm{p}=0.01){ }^{+}$: significantly lower than wheezy group $(\mathrm{p}=0.01)$.

informed consent was obtained from the parents and the study was approved by the Medical Ethics Committee of the Princess Margaret Hospital for Children.

\section{Exhaled nitric oxide measurements}

Exhaled NO was measured using a chemiluminescence analyser (NOA 280; Seivers Instruments Inc., Boulder, CO, USA). The sensitivity of the analyser for measurement of gas phase NO is $<1 \mathrm{ppb}$ by volume. The sampling flow into the analyser was $200 \mathrm{~mL} \cdot \mathrm{min}^{-1}$. Before each test the analyser was calibrated using a 2 point calibration, zero and $50 \mathrm{ppm}$ NO (BOC Gases, Perth, Australia), according to the manufacturers' instructions.

Tidal breathing method (off-line). Exhaled NO during TB was measured using an off-line reservoir collection technique. Five tidal breaths were collected into a gas sampling bag (GaSampler; Quintron Instrument company, Milwaukee, WI, USA) via a nonrebreathing valve (U-adapit "T" Adaptor; Allegiance Healthcare Corp., IL, USA) attached to a face mask. The authors have previously demonstrated that there is no difference in NO levels measured from either the mouth or the nose of sleeping infants [9], therefore all measurements were made with the mask covering both the mouth and nose. If ambient NO levels exceeded 5 ppb the infant inspired NO free air from a Douglas bag connected to the inspiratory limb of the nonrebreathing valve.

Single breath method. The SB technique has been described previously [5]. Briefly, an inflatable jacket was wrapped around the infant's chest and abdomen. Lung volume was then raised to an inflation pressure of $20 \mathrm{cmH}_{2} \mathrm{O}$ using a fan pump connected to a face mask via a computer-controlled circuit (Inflate-all; Coleman Inc., Wicket, KS, USA). Three consecutive inflation cycles were used and at the end of the third inhalation the jacket was inflated manually using a $3 \mathrm{~L}$ calibration syringe (Model No. 5530; Hans Rudolph Inc., Kansas City, MO, USA). During exhalation a mouth pressure of $20 \mathrm{~cm} \mathrm{H} \mathrm{H}_{2} \mathrm{O}$ was maintained to achieve a constant flow. Immediately prior to jacket inflation an intravenous cannula (Insyte 16 or $22 \mathrm{Ga}$; Becton Dickinson, Salt Lake City, UT, USA) was inserted into the expiratory limb of the system to increase expiratory resistance. A plateau of $\geqslant 0.5 \mathrm{~s}$ after $\mathrm{a} \geqslant 2 \mathrm{~s}$ exhalation was accepted.

In 26 infants measurements were made with an expiratory flow of both 11 and $40 \mathrm{~mL} \cdot \mathrm{s}^{-1}$. Flow was adjusted by changing the expiratory resistance while maintaining constant mouth pressure $\left(20 \mathrm{cmH}_{2} \mathrm{O}\right)$. To achieve a flow of $11 \mathrm{~mL} \cdot \mathrm{s}^{-1} \mathrm{a}$ $22 \mathrm{Ga}$ canula (Insyte; Becton Dickinson) was used as an expiratory resistance, while a $16 \mathrm{Ga}$ cannula (Insyte; Becton Dickinson) was used to obtain a flow of $40 \mathrm{~mL} \cdot \mathrm{s}^{-1}$.

\section{Statistical analyses}

Both TB [9] and SB [10] FENO have demonstrated a lognormal distribution so the data was transformed prior to analyses. The paired t-test and Pearson's correlation were used to compare FENO between the two SB expiratory flows (11 and $\left.40 \mathrm{~mL} \cdot \mathrm{s}^{-1}\right)$. Agreement between TB and SB levels was investigated using a Bland and Altmann plot [11] and Pearson's correlation. The Bland and Altmann plot revealed that the difference between the values increased with the mean so the analysis was repeated with the log transformed data. The effect of health status on FENO was investigated using a multiple linear regression model. Variables included in the model were health status, sex, age, height, weight, doctordiagnosed eczema and parental smoking. Transformed FENO levels were used as the outcome variable. Factors were removed in a stepwise fashion if they were not significant at the 0.05 level. A separate model was constructed for FENO collected with each of the two methods. Exhaled NO levels are reported as geometric mean with $95 \%$ confidence intervals (95\% CI).

\section{Results}

\section{Flow dependence of single breath method}

Geometric mean (95\% CI) FENO for expiratory flows of 11 and $40 \mathrm{~mL} \cdot \mathrm{s}^{-1}$ were $26.6 \mathrm{ppb}(20.0-35.3 \mathrm{ppb})$ and $19.9 \mathrm{ppb}(15.5-25.4 \mathrm{ppb})$, respectively. There was a significant difference $(\mathrm{p}<0.0001)$, and a good correlation $(\mathrm{r}=0.96)$ between these levels. Exhaled NO levels at $11 \mathrm{~mL} \cdot \mathrm{s}^{-1}$ were consistently higher than levels measured with a flow of $40 \mathrm{~mL} \cdot \mathrm{s}^{-1}$ (fig. 1).

\section{Comparison of single breath and tidal breathing methods}

There was poor agreement between FENO obtained using the two techniques (fig. 2). Measurements obtained by the SB method were generally higher than levels collected during TB. The mean difference between the measurements was -0.31 and

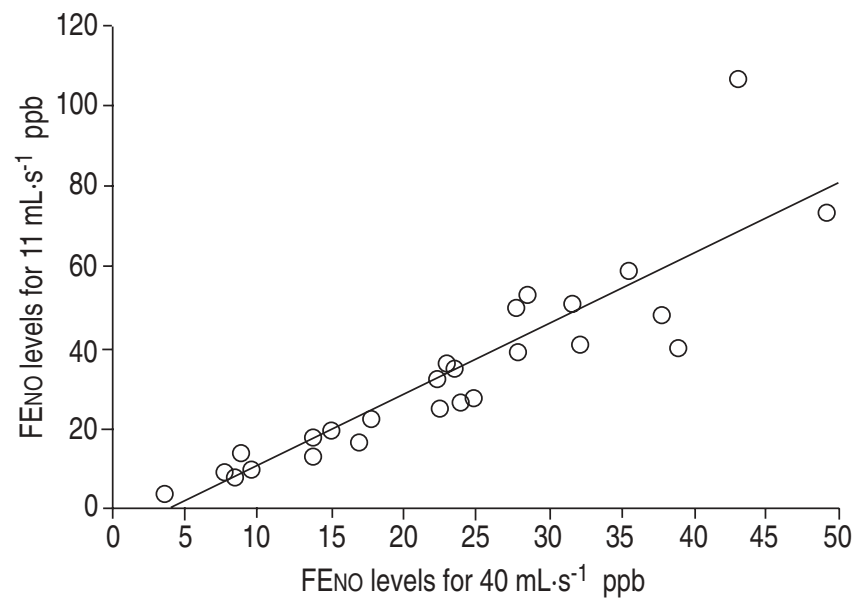

Fig. 1. - Comparison of fractional exhaled nitric oxide (FENO) values measured with two different expiratory flows $(\mathrm{r}=0.96)$. 


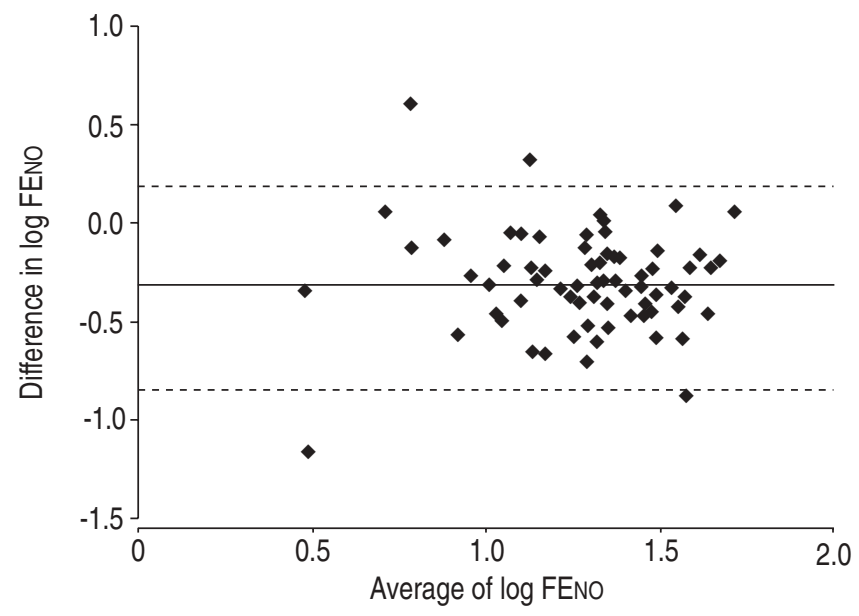

Fig. 2.-Agreement in log fractional exhaled nitric oxide (FENO) measured with the tidal breathing (TB) and single breath (SB) methods and difference in log FENO (SB-TB levels). - : mean difference between values obtained using the two methods; ----: represent the limits of agreement $( \pm 2 \mathrm{SD})$.

the limits of agreement were -0.82-0.2. TB levels were on average half SB levels with $95 \%$ of TB values ranging between $-84.8 \%$ and $+59.6 \%$ of SB values (fig. 2 ). SB FENO was significantly higher than TB levels for the whole group, as well as for each of the subgroups (healthy, wheezing or coughing). SB and TB values were significantly correlated $(r=0.60, p<0.0001)$.

\section{Exhaled nitric oxide and wheeze}

For SB measurements there was a significant difference in FENO between healthy and wheezy children (fig. 3a). Geometric mean levels (95\% CI) were $23.2 \mathrm{ppb}(18.3-29.4 \mathrm{ppb})$ for healthy infants, $27.9 \mathrm{ppb}(21.1-37.1 \mathrm{ppb})$ for infants with cough and $32.9 \mathrm{ppb}(26.1-41.6 \mathrm{ppb})$ for wheezy infants (difference between healthy and wheezy infants $\mathrm{p}=0.01$ ). FENO was significantly higher in females compared with males in this model (1.27-fold increase, $\mathrm{p}=0.04)$. There was no significant difference between healthy, wheezy or coughing children for TB values (fig. 3b). Geometric mean levels $(95 \%$ CI) of FENO for healthy, coughing and wheezing children were $13.8 \mathrm{ppb}(10.4-18.3 \mathrm{ppb}), 12.6 \mathrm{ppb}(8.0-20.0 \mathrm{ppb})$ and $15.7 \mathrm{ppb}(13.3-18.5 \mathrm{ppb})$, respectively $(\mathrm{p}=0.81)$. However, both age $(\mathrm{p}=0.022)$ and sex $(\mathrm{p}=0.037)$ were significantly associated with tidal FENO. Tidal FENO increased with age (0.1 ppb per week of age), while females had a 1.48-fold increase in TB FENO compared with males.

\section{Discussion}

Measuring FENO in wheezy infants may help to identify infants who wheeze due to asthma and are likely to have symptoms that persist through early childhood. In infants FENO has been measured during TB $[6,7,12]$ and with a modified SB technique [5]. In this study a poor agreement and only a moderate correlation between levels measured using both of these techniques was found, confirming that breathing patterns can considerably alter the concentration of NO in exhaled breath.

The advantages of the SB technique are that FENO is measured during constant expiratory flow and nasal NO contamination minimised [5]. WILDHABER et al. [13] have reported good $1 \mathrm{~h}$ and 4 week reproducibility of SB FENO. Flow dependence for FENO has been reported in both adults [14] and children [10] and the results from the current study at different expiratory
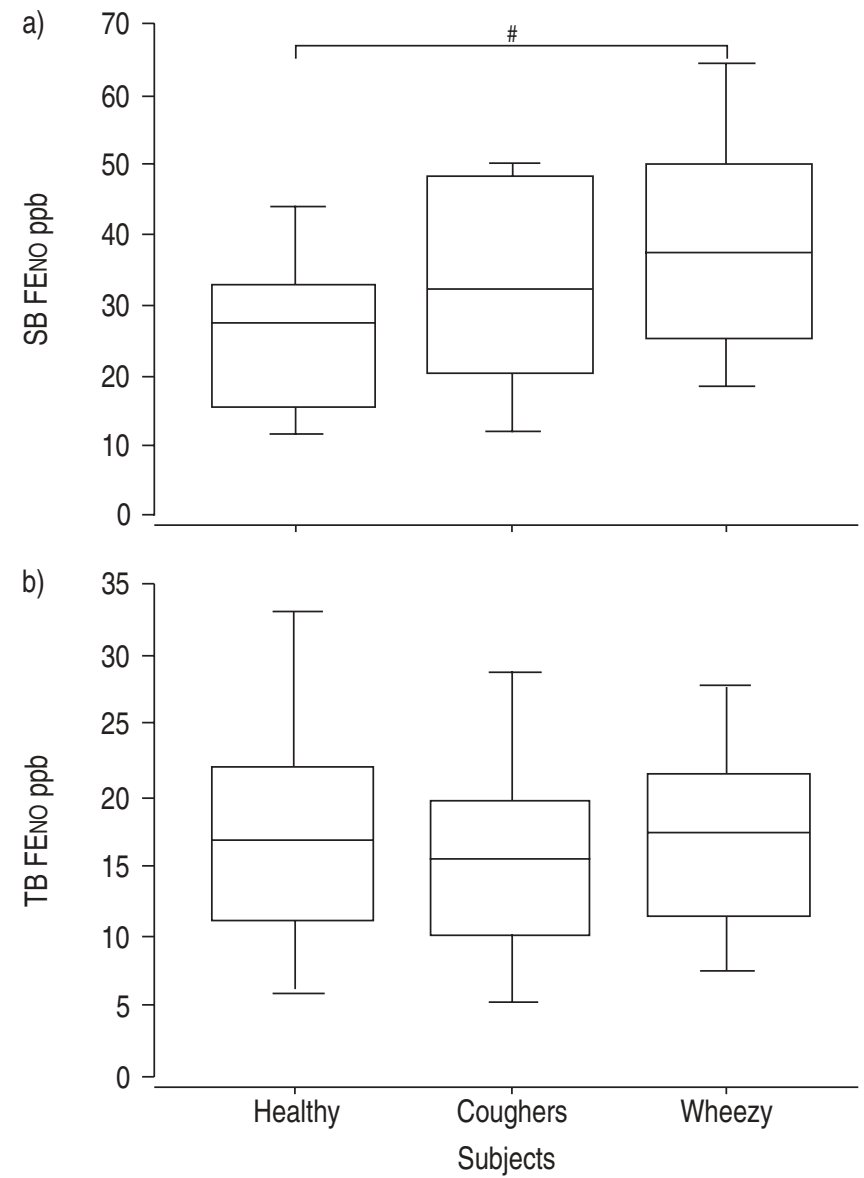

Fig. 3. - Box plots of fractional exhaled nitric oxide (FENO) in healthy, coughing and wheezy infants measured with a) the single breath (SB) method and $b$ ) the tidal breathing (TB) method. The box represents the median, 25th and 75th percentiles and the whiskers represent the 10 and 90 th percentiles. ${ }^{\#}$ : $\mathrm{p}=0.01$.

flows using the SB technique confirm earlier findings, in a much smaller group [5]. The authors were unable to obtain reliable data from all infants, however, a plateau in $86 \%$ of infants tested was successfully achieved. Unsuccessful attempts were mostly due to an inability to inhibit the infant's respiratory drive prior to the controlled exhalation. The SB technique used in infants results in a plateau at a comparable expired volume (based on forced vital capacity) to that recommended by the ATS for children aged $<12$ yrs [15].

The TB method is potentially a much less invasive and simpler collection method than the SB method but it is not possible to control for flow and nasal NO contamination. In the authors experience to obtain valid TB data, measurements need to be collected when an infant is asleep so that breathing is regular, as recommended by a joint European Respiratory Society/American Thoracic Society Taskforce [3]. Indeed, the authors have had difficulties collecting tidal breaths from infants who are awake and have found a large degree of variability in levels collected in conscious infants [9]. Similar problems have been experienced by other researchers measuring FENO in this age group [16].

There was poor agreement between FENO measured using the two techniques. Concentrations were consistently higher using the SB method and the difference increased with higher levels. This agrees with findings from a similar study in adults [17]. The higher concentrations recorded for the SB method in the current study is most likely to be due to lower expiratory flow. The flow used for the SB method was $11 \mathrm{~mL} \cdot \mathrm{s}^{-1}$ while 
for TB measurements the mean peak flow for the group was $128 \mathrm{~mL} \cdot \mathrm{s}^{-1}$. Interestingly, the correlation between SB and TB FENO, although significant, was only moderate $(r=0.60)$. This may reflect the variability of tidal flows but also may be due to other factors, such as nasal NO contamination and a dilution effect from the dead space during TB.

There was a significant difference in FENO concentrations between healthy children and children with wheeze when measured with the SB technique but not the TB technique. The results for the SB technique confirm a previous finding from the author's laboratory [5]. BARALDI et al. [4] collected FENO from infants using a TB technique and found that levels were increased during exacerbations of wheeze and returned to values similar to healthy children after treatment with inhaled corticosteroids. There have been no reports of TB FENO in untreated wheezing infants when they are well, although TB levels have previously been found to discriminate between both children [18, 19] and adults [17] with and without asthma. These studies are likely to have included more homogenous groups than in the present study. Indeed, not all of the infants with wheeze will have, or go on to develop, asthma. This is likely to explain why the TB method failed to distinguish healthy and wheezy populations in the current study. However, because the SB method uses a low expiratory flow, the measured FENO may be able to detect relatively small group differences.

In the current study, females had significantly higher FENO, both SB and TB, than males. This agrees with results from PiJnenBurg et al. [20] who measured SB FENO in children aged 4-8 yrs. Sex differences have not been reported in older prepubescent children using either TB [12] or SB [10] measurements, but there is increasing evidence that in adolescents [21] and adults [22-24] FENO is higher in males. These results suggest there is a maturational change in the relationship between FENO and sex. This could be due to relative changes in body mass [23] or differences in NO synthase activity between males and females [24]. Interestingly, TB FENO but not SB FENO increased with age. In contrast, an age effect has been reported in older children using SB methods [10, 21], but not the TB method [12]. In infants it could be expected that as expiratory flow increases with age FENO will decrease. The most likely explanation for this finding is an increased contribution of nasal $\mathrm{NO}$ as children grow older. Nasal NO levels increase with age probably as a result of the development and pneumatisation of the paranasal sinuses [25].

The ability of exhaled nitric oxide measurements in infancy to identify children with asthmatic wheeze remains to be determined. However, the results of the current study suggest that, in the research setting, single breath exhaled nitric oxide may be more sensitive than tidal breathing levels for differentiating between infants with and without airway inflammation. The usefulness of this test can only be determined in prospective studies. The infants in this cohort will be reassessed at school age.

\section{References}

1. Kharitonov SA, Barnes PJ. Clinical aspects of exhaled nitric oxide. Eur Respir J 2000; 16: 781-792.

2. Wright AL, Taussig LM. Lessons from long-term cohort studies. Childhood asthma. Eur Respir J 1998; 12: Suppl. 27, 17-22.

3. Baraldi E, de Jongste JC. Measurement of exhaled nitric oxide in children, 2001. Eur Respir J 2002; 20: 223-237.

4. Baraldi E, Dario C, Ongaro R, et al. Exhaled nitric oxide concentrations during treatment of wheezing exacerbation in infants and young children. Am J Respir Crit Care Med 1999; 159: $1284-1288$.
5. Wildhaber JH, Hall GL, Stick SM. Measurements of exhaled nitric oxide with the single-breath technique and positive expiratory pressure in infants. Am J Respir Crit Care Med 1999; 159: 74-78.

6. Ratjen F, Kavuk I, Gartig S, Wiesemann HG, Grasemann H. Airway nitric oxide in infants with acute wheezy bronchitis. Pediatr Allergy Immunol 2000; 11: 230-235.

7. Hall GL, Reinmann B, Wildhaber JH, Frey U. Tidal exhaled nitric oxide in healthy, unsedated newborn infants with prenatal tobacco exposure. J Appl Physiol 2002; 92: 59-66.

8. Turner DJ, Stick SM, Lesouef KL, Sly PD, Lesouef PN. A new technique to generate and assess forced expiration from raised lung volume in infants. Am J Respir Crit Care Med 1995; 151: 1441-1450.

9. Franklin PJ, Turner SW, Mutch R, Stick SM. Measuring exhaled nitric oxide in infants during tidal breathing: methodological issues. Pediatr Pulmonol 2004; 37: 24-30.

10. Franklin PJ, Taplin R, Stick SM. A community study of exhaled nitric oxide in healthy children. Am J Respir Crit Care Med 1999; 159: 69-73.

11. Bland JM, Altman DG. Statistical methods for assessing agreement between two methods of clinical measurement. Lancet 1986; 1: 307-310.

12. Baraldi E, Azzolin NM, Cracco A, Zacchello F. Reference values of exhaled nitric oxide for healthy children 6-15 years old. Pediatr Pulmonol 1999; 27: 54-58.

13. Wildhaber JH, Moller A, Hall GL, Sennhauser FH, Stick SM. Levels of exhaled nitric oxide in recurrently wheezy infants are decreased following inhaled steroid therapy. Schweiz Med Wochenschr 2000; 130: 529-534.

14. Silkoff PE, McClean PA, Slutsky AS, et al. Marked flowdependence of exhaled nitric oxide using a new technique to exclude nasal nitric oxide. Am J Respir Crit Care Med 1997; 155: 260-267.

15. American Thoracic Society. Recommendations for standardized procedures for the online and offline measurement of exhaled lower respiratory nitric oxide and nasal nitric oxide in adults and children - 1999. Am J Respir Crit Care Med 1999; 160: 2104-2117.

16. Godfrey S. Ups and downs of nitric oxide in chesty children. Am J Respir Crit Care Med 2002; 166: 438-439.

17. Rutgers SR, Meijer RJ, Kerstjens HA, van der Mark TW, Koeter GH, Postma DS. Nitric oxide measured with singlebreath and tidal-breathing methods in asthma and COPD. Eur Respir J 1998; 12: 816-819.

18. Artlich A, Busch T, Lewandowski K, Jonas S, Gortner L, Falke KJ. Childhood asthma: exhaled nitric oxide in relation to clinical symptoms. Eur Respir J 1999; 13: 1396-1401.

19. Visser MJ, de Wit MC, van Aalderen WM, Postma DS, Brand PL. Exhaled nitric oxide in children measured by tidal breathing method: differences between asthmatics and nonasthmatic controls. Pediatr Pulmonol 2000; 29: 434 437.

20. Pijnenburg MW, Lissenberg ET, Hofhuis W, et al. Exhaled nitric oxide measurements with dynamic flow restriction in children aged 4-8 yrs. Eur Respir J 2002; 20: 919-924.

21. Kissoon N, Duckworth LJ, Blake KV, Murphy SP, Taylor CL, Silkoff PE. FE(NO): relationship to exhalation rates and online versus bag collection in healthy adolescents. $\mathrm{Am}$ J Respir Crit Care Med 2000; 162: 539-545.

22. Jilma B, Kastner J, Mensik C, et al. Sex differences in concentrations of exhaled nitric oxide and plasma nitrate. Life Sci 1996; 58: 469-476.

23. Tsang KW, Ip SK, Leung R, et al. Exhaled nitric oxide: the effects of age, gender and body size. Lung 2001; 179: 83-91.

24. Grasemann H, van's Gravesande KS, Buscher R, Drazen JM, Ratjen F. Effects of sex and of gene variants in constitutive nitric oxide synthases on exhaled nitric oxide. Am J Respir Crit Care Med 2003; 167: 1113-1116.

25. Lundberg JO, Farkas-Szallasi T, Weitzberg E, et al. High nitric oxide production in human paranasal sinuses. Nature Med 1995; 1: 370-373. 